\title{
Polyethylene glycol vs. sodium phosphate for bowel preparation: A treatment arm meta- analysis of randomized controlled trials
}

Ravi Juluri ${ }^{*}$, George Eckert ${ }^{2}$ and Thomas F Imperiale Th, $^{3,5}$

\begin{abstract}
Background: Results of meta-analyses of randomized trials comparing PEG and NaP are inconsistent and have not included trials comparing either or both preps to less traditional ones.

AIM: To perform a meta-analysis by treatment arm.

Methods: Using MEDLINE and EMBASE, we identified English-language trials published from 1990 to 2008 that included PEG and/or NaP, and aggregated them by treatment arm into: 4 liter (L) PEG; 2 L PEG; split-dose PEG; two $45 \mathrm{ml}$ doses of $\mathrm{NaP}+/$ - adjunctive medication; and $\mathrm{NaP}$ tablets. We compared prep quality and the proportion completing the prep.
\end{abstract}

Results: Among 71 trials (patient $N=10,201)$, excellent prep quality was present in 34\% (Cl, 26-41\%) for 4 L PEG alone; 39\% (Cl, 26-51\%) for 2 L PEG; 37\% (Cl, 28-46\%) for split-dose PEG; 42\% (Cl, 33-51\%) for NaP solution; 44\% (Cl, 38-51\%) for NaP with adjunctive meds; and 58\% (Cl, 49-67\%) for NaP tablets. Patients receiving NaP were more likely to complete the prep (97\% [Cl, 96-98\%] vs. 90\% [Cl, 87-92\%] for 4L PEG alone); however, completion rates for 2L PEG (98\%) and split dose PEG (95\%) were similar to NaP.

Conclusions: $\mathrm{NaP}$ tablets resulted in better prep quality and higher completion rates compared to other regimens. In comparisons limited by sample size, split dose PEG was not statistically different from NaP solution for completion rate or prep quality.

Keywords: Colonoscopy Bowel preparation, Polyethylene Glycol, Sodium Phosphate

\section{Background}

Colonoscopy is a well-established procedure for screening, diagnosis and treatment of colorectal disorders $[1,2]$. For colonoscopy to be effective, adequate preparation of the bowel is required for visualization of the colonic mucosa. To achieve this, a bowel preparation should be tolerable, safe, effective and convenient. Bowel preparation is considered to be the main obstacle for patients undergoing colonoscopy [3]. The aversion toward bowel preparation may be related to its taste, fluid volume ingested, or side effects such as nausea, bloating and vomiting.

Polyethylene glycol (PEG) (NuLYTELY, Half Lytely, and GoLYTELY; Braintree Laboratories, Inc, Braintree, MA;

\footnotetext{
* Correspondence: rjuluri@iuhealth.org

'Indiana University Health Physicians, Indianapolis, Indiana, USA

Full list of author information is available at the end of the article
}

Colyte; Schwarz Pharma, Milwaukee, WI, and MoviPrep; Salix Pharmaceutical, Inc, Morrisville, NC) and sodium phosphate (NaP) tablets (Visicol and OsmoPrep Tablets; Salix Pharmaceuticals, Inc, Morrisville, NC), NaP solution (Fleet Phospho-soda; C.B. Fleet Company, Inc, Lynchburg, VA), are the most widely used agents for colon cleansing. Polyethylene glycol is an orally administered isotonic solution introduced in 1980 [4]. Since PEG is nondigestible and nonabsorbable, it cleanses the colon by purging of intraluminal contents [5]. Because it is iso-osmolar with plasma, the large volume of PEG does not result in significant fluid shifts. It has been shown to be highly effective when taken as instructed (4L of PEG solution). However, the efficacy of standard 4 L PEG outside of clinical trials is compromised by poor patient compliance. The large volume and taste are the main factors that contribute to poor patient compliance and tolerability [6-8], which led

\section{C) Biomed Central}


to development of reduced volume PEG solution with or without laxatives, sulfate-free, and flavored PEG solutions (Half Lytely, NuLYTELY) in an attempt to reduce the sulfate odor and improve taste [9]. In some studies, split-dose PEG has been more effective than standard 4L PEG $[10,11]$.

Sodium phosphate (NaP), a buffered saline laxative, gained popularity as an alternative method for colonic preparation due to its smaller volume. Containing monobasic sodium phosphate and dibasic sodium phosphate, $\mathrm{NaP}$ acts as an osmotic laxative, cleansing the colon by drawing fluids into the gastrointestinal tract. Several randomized trials and meta-analyses comparing PEG and $\mathrm{NaP}$ have suggested that $\mathrm{NaP}$ is safe, better tolerated, cost-effective, and equally or more effective $[5,12-15]$. NaP tablets (Visicol ${ }^{\circledR}$ ) were designed to improve the taste and reduce the volume required for bowel preparation. NaP tablets contain microcrystalline cellulose which can be deposited in the colon requiring additional irrigation. A newer residue-free formulation of sodium phosphate tablets (OsmoPrepTM) was introduced [16] to overcome this limitation.

Previous meta-analyses, $[5,17,18]$ have included headto-head trials of PEG vs. NaP but have not included trials comparing either or both of these preps to other, less commonly used preps. The objective of this metaanalysis was to quantify and compare the effect of the two bowel preps on efficacy of and patient adherence to $\mathrm{NaP}$ vs. PEG for elective colonoscopy.

\section{Methods}

\section{Search Strategy and selection criteria}

We searched the medical literature from January 1990 to December 2008 using MEDLINE and EMBASE bibliographic databases and identified all relevant English language publications. The search strategy used the following MeSH terms: 1) colonoscopy, 2) polyethylene glycol, 3) phosphates, 4) cathartics and 5) bowel prep. We limited these sets of articles to diagnostic and therapeutic uses and to human studies published in English. In addition, we hand-searched the reference lists of every selected primary study for additional trials. The following criteria were used to select studies for inclusion: 1) study design: randomized controlled trial (RCT), 2) patient population: adult patients undergoing elective colonoscopy, 3) year of publication (1990-2008), 4) dosing and frequency schedules of PEG and $\mathrm{NaP}$ commonly used in clinical practice. We excluded duplicate trials, those that lacked categorical data on both prep quality and adherence; review articles; editorials; and letters to the editor.

\section{Assembling the treatment arms}

The analysis compared on treatment arms rather than individual trials. Each trial was disassembled and aggregated by treatment arm $[19,20]$ into one of the following groups: 1) 4 liter PEG +/- adjunctive medications (e.g., dulcolax), 2) 2 liter PEG, 3) Split-dose PEG, 4) $\mathrm{NaP}$ solution - two $45 \mathrm{ml}$ doses +/- adjunctive medications, 5) NaP tablets. Disassembly of the trials into treatment arms was based on the determination that the treatment arms were clinically homogeneous in composition. This determination was based on a qualitative assessment of similarity of the trial populations, study settings, prep regimens, ratings of bowel prep quality, and outcomes. All descriptive and quantitative data were extracted from the papers to an analytic database. If the data for the particular variable were not available, that variable was excluded from analysis and no assumption was made about the missing data.

\section{Quantitative analysis}

Descriptive data were extracted to determine clinical similarity of the individual trials; extracted quantitative data included the number of subjects in each treatment arms and those with each outcome. Discrepancies in data extraction were resolved in discussion. For pooling procedures, the extracted data were combined across treatment arms rather than across individual trials. We assumed the presence of clinical heterogeneity because of variation in factors that were not consistently described in each trial, such as prep timing, consumption of additional liquids, and dietary instructions. We combined the data using the random effects model developed by DerSimonian-Laird [21], which adjusts for variation within treatment arms and provides a more conservative estimate an effect by providing wider confidence intervals (CIs). We compared prep quality (excellent, good, fair, poor) and the percent of persons completing the prep using weighted, summary- level proportions and 95\% CI. All analyses and calculations were done using r-meta library (version 2.14) for the statistical software R (version 2.5.1).

\section{Results}

\section{Descriptive findings}

One hundred seventy four abstracts were obtained from 1990 through 2008 using MEDLINE and EMBASE; 50 were excluded as they were either published prior to 1990 ( $\mathrm{n}=18$ ), involved bowel preparation for non colonoscopy use $(n=11)$, were published in foreign language $(n=8)$, or were non-randomized controlled trials $(\mathrm{n}=13)$. Of the 124 randomized controlled trials included for full text review, 53 trials were excluded. The number of articles and reasons for exclusion were as follows: trials which included a pediatric population ( $\mathrm{n}=6)$; trials that did not include PEG or NaP $(\mathrm{n}=24)$; trials with no categorical data $(\mathrm{n}=12)$; and trials with non-traditional doses of either prep (e.g., single dose $3 \mathrm{~L}$ 
or 6L PEG solutions regimen, single dose $\mathrm{NaP}(45 \mathrm{~mL}$ or $90 \mathrm{~mL} ; \mathrm{n}=11$ ) were excluded (Figure 1 ).

For analysis, we included 71 randomized controlled trials [6-8,10-14,16,22-83] involving 10,201 patients. Trial aggregation by treatment arm resulted in the following prep arms: 4 liter PEG with and without adjunctive medications (e.g., metoclopramide, dulcolax); 2 liter PEG; split-dose PEG; NaP solution - two $45 \mathrm{ml}$ doses with and without adjunctive medications; and $\mathrm{NaP}$ tablets. All low volume PEG trials (i.e., 2 liter) invariably used an adjunctive medication such as bisacodyl (70\%), senna (20\%), and magnesium citrate or ascorbic acid (10\%). Trials that used split dose PEG regimen either divided a 4 liter dose into 2 liter the day before and 2 liter on the day of the procedure or divided a 3 liter dose into 2 liter the day before and 1 liter the day of the procedure.

Descriptive data for each treatment arm is shown in Table 1 . Overall mean age was 58 years; $49 \%$ of the study participants were men. At least 68 (95.7\%) of 71 trials were investigator-blinded. The trials had comparable study populations; individual trial inclusion criteria consisted of patients with indications for screening or diagnostic colonoscopy. Exclusion criteria generally included congestive heart failure, recent myocardial infarction, renal insufficiency, and cirrhosis with ascites. All trials used comparable scales for rating bowel prep quality [6]: excellent prep quality was defined as a small volume of clear liquid or greater than $95 \%$ of surface seen; good prep quality was defined as large volume of clear liquid covering $5 \%$ to $25 \%$ of the surface but greater than $90 \%$ of surface seen; fair prep quality was defined as some semi-solid stool that could be suctioned or washed away but greater than $90 \%$ of surface seen; and poor prep quality was defined as: semi-solid stool that could not be suctioned or washed away and less than $90 \%$ of the surface seen. A few trials defined prep

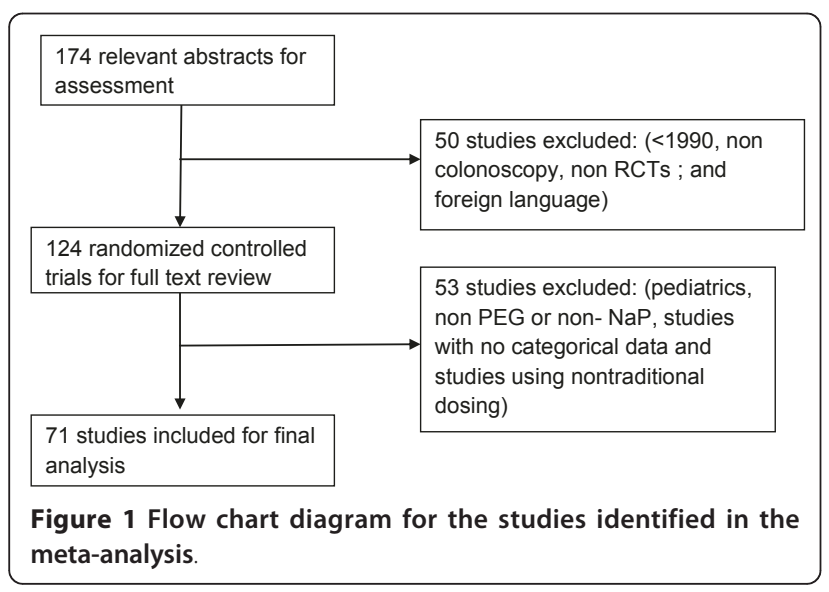

quality as "excellent or good", satisfactory (excellent or good), or unsatisfactory (fair or poor). These definitions were comparable to the individual quality components of the four point scale for prep quality [6].

The method of preparation of PEG and NaP were similar among the trials with some variation in the timing of prep consumption. Dietary recommendations the day before colonoscopy varied from regular to a clear liquid diet for lunch to a full clear liquid diet in the evening. Co-interventions accompanying trials with 2 liter PEG, 4 liter PEG with adjunctive medications, and $\mathrm{NaP}$ solution with adjunctive medications were either taken separately and only rarely in combination with the study preparation, and included magnesium citrate, metoclopramide, psyllium, bisacodyl, cisapride, ascorbic acid, senna, and simethicone.

\section{Quantitative findings}

The proportion of persons with excellent prep quality were $42.1 \%$ (CI, 33-51\%) for NaP solution alone; $44.4 \%$ (CI, 38-51\%) for NaP with adjunctive meds; $58.2 \%$ (CI, 49-67\%) for NaP tablets; 33.7\% (CI, 26-41\%) for 4 liter PEG alone; $38.7 \%$ (CI, 26-51\%) for 2 literL PEG; and $37.2 \%$ (CI, 28-46\%) for split-dose PEG (Table 2). Based on the criterion of minimal or no overlap of the $95 \%$ $\mathrm{CIs}, \mathrm{NaP}$ tablets resulted in a greater likelihood of achieving an excellent quality prep than did all PEG groups, while NaP solution was intermediate. All PEG groups were essentially equivalent with respect to prep quality (Table 2).

The composite measure of excellent or good quality preparation was achieved by $76.3 \%(\mathrm{CI}, 72-81 \%)$ of those who used NaP solution alone; by $68.7 \%$ (CI, 54-84\%) of those who used $\mathrm{NaP}$ solution with adjunctive medication; and by $87.8 \%$ (CI, 83-93\%) of those who used $\mathrm{NaP}$ tablets (Table 3 and Figure 2). For the PEG treatment subgroups, an excellent or good prep quality was achieved by $71.5 \%$ (CI, 64-80\%) for 4 liter PEG alone; in $67.8 \%$ (CI, 49-87\%) for 4 liter PEG with adjunctive medications; in $69.2 \%$ (CI, 58-81\%) for 2 liter PEG; and in 66.4\% (CI, 31-100\%) for split-dose PEG. Use of NaP tablets was more likely to result in good or excellent quality prep than both $\mathrm{NaP}$ solution groups. When compared to the PEG groups, $\mathrm{NaP}$ tablets were superior to both 4 liter and 2 liter PEG groups and were superior to 4 liter PEG with adjunctive medications, with minimally overlapping CIs. All comparisons that included split-dose PEG resulted in significant overlap of the 95\% CIs because of both the relatively small numbers of subjects in this group and the variation in results among the individual studies. Thus, while split-dose PEG was not statistically different from any of the other groups, the proportion of subjects with a good or excellent 
Table 1 Descriptive data for each prep treatment arm

\begin{tabular}{ccccc}
\hline Prep Treatment Arm & \# of Treatment Arms & \# of Pts & Mean Age, y (range) & \% Males (range) \\
\hline NaP Solution alone & 31 & 2463 & $58.2(51-84)$ & $46.6(20-77)$ \\
NaP Solution with adjunctive meds & 5 & 358 & $56.3(52-60)$ & $44.6(31-52)$ \\
NaP Tablets & 7 & 1793 & $56.3(56-58)$ & $43.7(40-49)$ \\
4L PEG alone & 33 & 2729 & $59.3(52-84)$ & $48.2(14-99)$ \\
4L PEG with adjunctive meds & 6 & 372 & $63.3(58-81)$ & $57.9(34-100)$ \\
2L PEG & 17 & 1919 & $58.6(54-62)$ & $52.6(30-99)$ \\
Split dose PEG & 5 & 567 & $55.3(52-57)$ & $49.6(37-65)$ \\
\hline
\end{tabular}

quality prep was numerically lower than all groups and to a clinically-important degree as compared with $\mathrm{NaP}$ tablets.

Prep completion rates are shown in Table 3 and Figure 3. Patients who received $\mathrm{NaP}$ either alone in liquid form or in tablet form were more likely to complete the prep (97.3\% [CI, 96-98\%] and 97.2\% [CI, 95-99] respectively, vs. 89.5\% [CI, 87-92\%] for PEG). However, completion rates for $2 \mathrm{~L}$ PEG (98\%) and split-dose PEG (95\%) were similar to NaP.

\section{Discussion}

This meta-analysis examined 71 randomized controlled trials that included $\mathrm{NaP}$ or PEG solution or both for bowel preparation prior to elective, outpatient colonoscopy. The findings indicate that $\mathrm{NaP}$ resulted in an excellent quality prep more often than PEG. Further, based on minimal or no overlap of the $95 \%$ CIs, NaP tablets resulted in a greater likelihood of achieving an excellent quality prep than did all PEG groups, while $\mathrm{NaP}$ solution was in between. There was no difference in prep quality among the various PEG subgroups. Among treatments arms where prep quality could be quantified as a composite of excellent or good, $\mathrm{NaP}$ tablets $(87.8 \%)$ were numerically superior to all other forms of either prep. There was minimal overlap of the 95\% CI of NaP tablets with those of both $\mathrm{NaP}$ solution and 4 L PEG arms, both of which included adjunctive medications. Despite an absolute difference of just over 21\% between NaP tablets and split dose 4 L PEG that favored NaP tablets, the CIs showed a large degree of overlap, most likely due to the imprecision of the individual trial point estimate for split dose PEG. Finally, among the trials that included completion rates, $\mathrm{NaP}$ was more likely to be completed than PEG, with the exception of the split dose PEG regimen.

Previous meta-analyses of head-to-head trials of PEG vs. $\mathrm{NaP}$ have reported that sodium phosphate is more effective, better tolerated, and less costly than PEG [5,18]. However, in 2007 a meta-analysis by Belsey et al reported that no single bowel preparation was consistently superior to others [17]. Both meta-analyses excluded data from trials comparing either or both of these preps to other, less commonly used preps.

This analysis has strengths and limitations. One strength is the breadth of our search strategy and analysis, as we included studies that have been excluded in other systematic reviews. Another strength is the clinical homogeneity of the patient population studied: all groups were comprised of outpatients undergoing elective colonoscopy. Further, as best we could determine, the study populations, even after re-assembly by treatment arm, appear to be demographically and clinically comparable. Finally, the large sample size of this analysis provides reasonable precision for most of the point estimates of effect for both efficacy and tolerability.

With regard to limitations, the potential for clinical heterogeneity is always present when combining trials, particularly for factors that were not measured. The possibility of clinical heterogeneity appears to be low; to minimize its effects, we used a random effects model, which accounts for heterogeneity by both providing a point estimate that is less weighted by the studies with larger sample sizes and resulting in wider confidence intervals. Several candidate factors may contribute to clinical and/or methodological heterogeneity among

Table 2 Prep quality by treatment arm

\begin{tabular}{|c|c|c|c|c|c|}
\hline Prep Treatment Arm & \# of Treatment Arms & $\%$ Excellent $(95 \% \mathrm{CI})$ & $\%$ Good $(95 \% \mathrm{Cl})$ & $\%$ Fair $(95 \% \mathrm{Cl})$ & $\%$ Poor $(95 \% \mathrm{Cl})$ \\
\hline NaP Solution alone & 22 & $42.1(33-51)$ & $31.0(25-37)$ & $16.4(13-20)$ & $7.0(5-9)$ \\
\hline NaP Sol'n with adjunctive meds & 3 & $44.4(38-51)$ & $23.0(18-28)$ & $26.2(21-32)$ & $5.6(2-9)$ \\
\hline NaP tablets & 7 & $58.2(49-67)$ & $28.8(22-36)$ & $9.9(7-14)$ & $1.4(0.6-2)$ \\
\hline 4L PEG alone & 23 & $33.7(26-41)$ & $36.8(33-41)$ & $23.3(15-31)$ & $5.9(4-8)$ \\
\hline 2L PEG & 11 & $38.7(26-51)$ & $38.6(29-48)$ & $23.5(13-34)$ & $4.3(2-6)$ \\
\hline Split dose PEG & 5 & $37.2(28-46)$ & $43.0(35-51)$ & $11.1(5-17)$ & $5.7(1-10)$ \\
\hline
\end{tabular}


Table 3 Prep quality (Excellent/Good) and completion rates by treatment arm

\begin{tabular}{ccccc}
\hline Prep Treatment Arm & \# of Treatment Arms & \# of Pts & \% Good or Excellent $\mathbf{9 5 \% ~ C l )}$ & \% Prep Completed (95\% Cl) \\
\hline NaP Solution alone & 31 & 2463 & $76.3(72-81)$ & $97.3(96-98)$ \\
NaP Sol'n with adjunctive meds & 5 & 358 & $68.7(54-84)$ & $92.9(85-99)$ \\
NaP Tablets & 7 & 1793 & $87.8(83-93)$ & $97.2(95-99)$ \\
4L PEG alone & 33 & 2729 & $71.5(64-80)$ & $89.5(87-92)$ \\
4L PEG with adjunctive meds & 6 & 372 & $67.8(49-87)$ & $95.3(86-100)$ \\
2L PEG & 17 & 1919 & $69.2(58-81)$ & $98.0(96-100)$ \\
Split dose PEG & 5 & 567 & $66.4(31-100)$ & $95.4(86-100)$ \\
\hline
\end{tabular}

trials. One factor is variation in timing of bowel prep. The time at which the bowel prep was started was not uniform among the trials ranging from 2:00 PM in the afternoon to 7:00 PM in the evening the day before the scheduled procedure. This may have affected those patients undergoing colonoscopy in the afternoon by affecting prep quality particularly in the right colon, where intestinal chyme can accumulate, obscuring the mucosa. Another factor potentially contributing to heterogeneity is the variation in dietary instructions prior to and during the prep, which also were not uniform among the trials, and which ranged from a regular diet to a clear liquid diet for lunch and clear liquid diet in the evening.

A second limitation is the uncertain acceptability of the "treatment-arm" method of doing meta-analysis. While this method has been used previously for comparing treatments for rheumatoid arthritis [19], for prevention of deep venous thrombosis following total hip replacement [84] and for treatment of premature

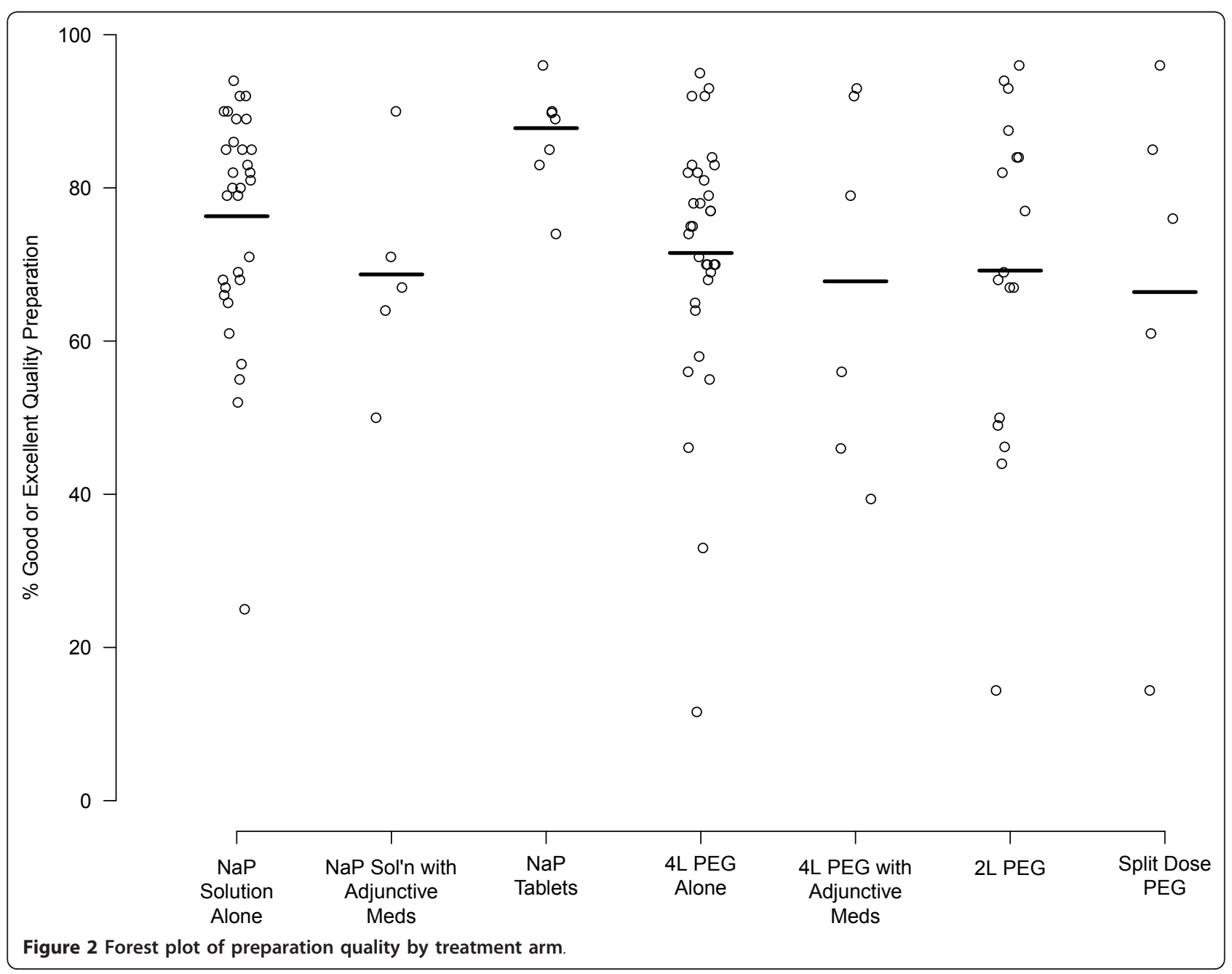




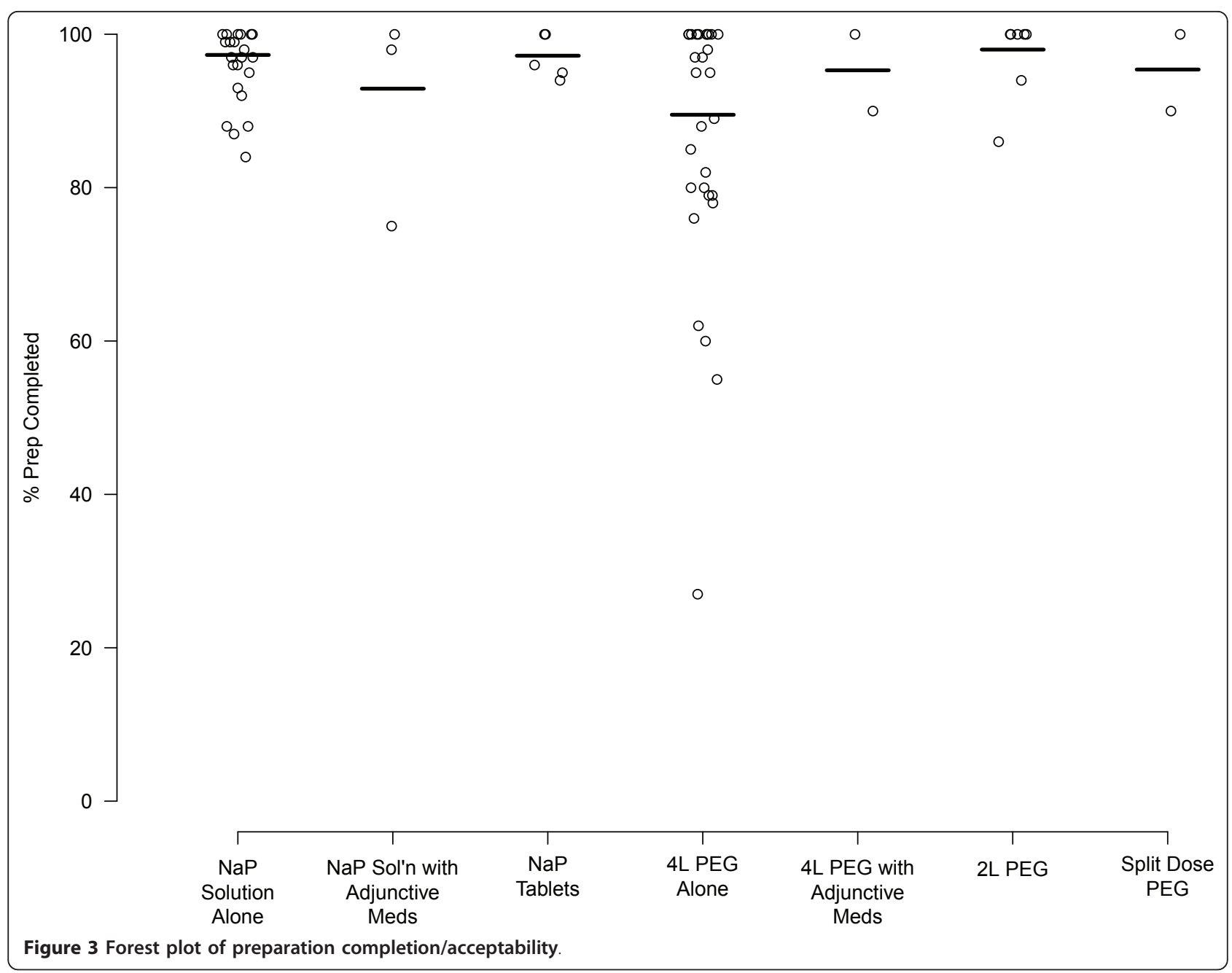

labor [85], its validity is less well established than is head-to-head meta-analysis where comparators are the same in all studies. Limiting the analysis to a head-tohead comparison would not have allowed consideration of evidence from trials where either NaP or PEG was compared to another bowel preparation. An alternative to our "treatment-arm" approach is a mixed treatment comparison or "network" meta-analysis, which is another way of quantitatively aggregating data across studies containing disparate comparators $[86,87]$. It allows comparison of multiple treatments, combining direct and indirect evidence in a single analysis. While head-to-head meta-analysis and network meta-analysis of the same data have been compared [88], there are no comparative analyses between network and treatment-arm meta-analyses. In the absence of such comparative data, it remains uncertain which method is most appropriate for synthesizing quantitative data, and under which circumstances the two methods differ in results.
A third potential factor is the variation in definitions of patient tolerance of the prep. While some trials defined patient tolerance by different parameters (e.g. completion rates, willingness to repeat the prep, palatability and adverse affects), others defined patient tolerance as a single parameter and reported it as a single cumulative estimate.

In recent years, three reports have described 22 patients who developed renal insufficiency due to nephrocalcinosis that was temporally associated with use of $\mathrm{NaP}$ for colonoscopy prep, 4 of whom progressed to end stage renal disease requiring dialysis [89-91]. The majority of these patients had co-morbid conditions such as diabetes mellitus, hypertension (treated with angiotensin-converting enzyme inhibitors [ACE-I] or angiotensin receptor blockers [ARBs] or diuretics), preexisting renal insufficiency, were elderly, or had small bowel disease that resulted in calcium and vitamin D malabsorption. Renal biopsies of many of the cases showed nephrocalcinosis with intra-tubular deposition 
of calcium-phosphate. The term for this pathologic condition is acute phosphate nephropathy (APN). The histopathology suggests that sodium phosphate ingestion leads to obstructive calcium-phosphate crystalluria followed by acute intra-tubular nephrocalcinosis. These reports have recently raised concerns that led Food and Drug Administration [92] to announce a safety alert in December 2008, stating that a boxed warning would be added to the labeling on prescription OSPs (Visicol and OsmoPrep) and recommending against use of over-thecounter OSPs for bowel preparation. Shortly after this announcement, all over-the-counter $\mathrm{NaP}$ products were voluntarily removed from the market, with a subsequent sharp decline in use of $\mathrm{NaP}$ solution.

Despite the FDA's action and resulting reaction, the published data suggest that absolute risk of APN is very low $[93,94]$. Further, a recent systematic review and meta-analysis of seven controlled studies (patient $\mathrm{N}=$ 14,520 ) of the effects of $\mathrm{NaP}$ versus comparator on kidney function showed that there is significant clinical heterogeneity in the populations studied, study methods, definition of kidney injury, and results [95]. Quantitatively, the pooled odds ratio for kidney injury among NaP-treated patients ranged from 1.08 (CI, 0.71-1.62) to 1.22 (CI, 0.77-1.92). The investigators concluded that it was not possible to discern whether there is a true association between $\mathrm{NaP}$ and kidney injury.

The results of this meta-analysis apply to patients undergoing elective colonoscopy who do not have a history of co-morbid conditions such as renal insufficiency, recent myocardial infarction, ascites due to cirrhosis, and congestive heart failure. Further, NaP should not be used by patients with suspected or established inflammatory bowel diseases because of aphthous ulcerations it may cause [96]. While NaP solution is not currently available, tablet forms of $\mathrm{NaP}$ remain available by prescription only. Physicians should be aware of the risk of acute kidney injury with $\mathrm{NaP}$ preparations and should not use it in older patients, in those with preexisting renal insufficiency, and in patients on medications that can affect volume status or renal function (diuretics, ACE inhibitors, and ARBs). Further, all patients should be encouraged to adequately hydrate themselves prior to and while using $\mathrm{NaP}$ preparations.

\section{Conclusions}

In conclusion, this treatment-arm meta-analysis of $\mathrm{NaP}$ and PEG suggests that $\mathrm{NaP}$ tablets result in a better quality prep than NaP solution, 2L PEG, and 4 L PEG alone. $\mathrm{NaP}$ is more likely to be completed overall. In comparisons limited by sample size, split dose PEG was not statistically different from $\mathrm{NaP}$ for both completion rate and prep quality. Head-to-head trials between split- dose PEG and NaP tablets would be useful in further defining the relative efficacy of these two regimens.

\section{Acknowledgements}

Supported by in part by NIH grant \#DK K24 02756 (TFI).

\section{Author details}

${ }^{1}$ Indiana University Health Physicians, Indianapolis, Indiana, USA.

${ }^{2}$ Department of Medicine, Division of Biostatistics, Indiana University School of Medicine, Indianapolis, Indiana, USA. ${ }^{3}$ Department of Medicine, Division of Gastroenterology and Hepatology, Indiana University School of Medicine, Indianapolis, Indiana, USA. ${ }^{4}$ Regenstrief Institute, Inc, Indianapolis, Indiana, USA. ${ }^{5}$ Center of Excellence for Implementing Evidence-based Practice, Richard L. Roudebush VAMC, Indianapolis, Indiana, USA.

\section{Authors' contributions}

RJ: carried out data collection, analysis and interpretation of the data, sequence alignment and drafting the manuscript. GE: carried out the statistical analysis and helped in drafting relevant statistical discussion in the manuscript. TFI: carried out- analysis and interpretation of the data, conceived of the analysis, participated in sequence alignment and final approval of the manuscript. All authors read and approved the final manuscript.

\section{Competing interests}

The authors declare that they have no competing interests.

Received: 4 June 2010 Accepted: 14 April 2011 Published: 14 April 2011

\section{References}

1. Wexner SD, Beck DE, Baron TH, Fanelli RD, Hyman N, Shen B, Wasco KE, American Society of C, Rectal S, American Society for Gastrointestinal E, et al: A consensus document on bowel preparation before colonoscopy: prepared by a task force from the American Society of Colon and Rectal Surgeons (ASCRS), the American Society for Gastrointestinal Endoscopy (ASGE), and the Society of American Gastrointestinal and Endoscopic Surgeons (SAGES). Gastrointest Endosc 2006, 63:894-909.

2. Davila RE, Rajan E, Baron TH, Adler DG, Egan JV, Faigel DO, Gan SI, Hirota WK, Leighton JA, Lichtenstein D, et al: ASGE guideline: colorectal cancer screening and surveillance.[erratum appears in Gastrointest Endosc. 2006 May;63(6):892 Note: Adler, Douglas G [added]; Egan, James V [added]; Faigel, Douglas O [added]; Gan, Seng-lan [added]; Hirota, William K [added]; Leighton, Jonathan A [added]; Lichtenstein, David [added]; Qureshi, Waqar A [added]; Shen, Bo [added]; Zuckerman, Marc J [added]; VanGuilder, Trina [added]; Fanelli, Robert D [added]]. Gastrointestinal Endoscopy 2006, 63:546-557.

3. Harewood GC, Wiersema MJ, Melton LJ, Harewood GC, Wiersema MJ, Melton LJ: A prospective, controlled assessment of factors influencing acceptance of screening colonoscopy. American Journal of Gastroenterology 2002, 97:3186-3194.

4. Davis GR, Santa Ana CA, Morawski SG, Fordtran JS: Development of a lavage solution associated with minimal water and electrolyte absorption or secretion. Gastroenterology 1980, 78:991-995.

5. Hsu CW, Imperiale TF: Meta-analysis and cost comparison of polyethylene glycol lavage versus sodium phosphate for colonoscopy preparation. Gastrointestinal Endoscopy 1998, 48:276-282.

6. Aronchick CA, Lipshutz WH, Wright SH, Dufrayne F, Bergman G: A nove tableted purgative for colonoscopic preparation: efficacy and safety comparisons with Colyte and Fleet Phospho-Soda. Gastrointestinal Endoscopy 2000, 52:346-352.

7. Radaelli F, Meucci G, Imperiali G, Spinzi G, Strocchi E, Terruzzi V, Minoli G: High-dose senna compared with conventional PEG-ES lavage as bowel preparation for elective colonoscopy: a prospective, randomized, investigator-blinded trial. American Journal of Gastroenterology 2005, 100:2674-2680

8. Hayes A, Buffum M, Fuller D: Bowel preparation comparison: flavored versus unflavored colyte. Gastroenterology Nursing 2003, 26:106-109

9. Fordtran JS, Santa Ana CA, Cleveland Mv B: A low-sodium solution for gastrointestinal lavage. Gastroenterology 1990, 98:11-16. 
10. El Sayed AMA, Kanafani ZA, Mourad FH, Soweid AM, Barada KA, Adorian CS, Nasreddine WA, Sharara Al: A randomized single-blind trial of whole versus split-dose polyethylene glycol-electrolyte solution for colonoscopy preparation. Gastrointestinal Endoscopy 2003, 58:36-40.

11. Aoun E, Abdul-Baki H, Azar C, Mourad F, Barada K, Berro Z, Tarchichi M, Sharara Al: A randomized single-blind trial of split-dose PEG-electrolyte solution without dietary restriction compared with whole dose PEGelectrolyte solution with dietary restriction for colonoscopy preparation. Gastrointestinal Endoscopy 2005, 62:213-218.

12. Vanner SJ, MacDonald PH, Paterson WG, Prentice RS, Da Costa LR, Beck IT: A randomized prospective trial comparing oral sodium phosphate with standard polyethylene glycol-based lavage solution (Golytely) in the preparation of patients for colonoscopy.[see comment]. American Journal of Gastroenterology 1990, 85:422-427.

13. Kolts BE, Lyles WE, Achem SR, Burton L, Geller AJ, MacMath T: A comparison of the effectiveness and patient tolerance of oral sodium phosphate, castor oil, and standard electrolyte lavage for colonoscopy or sigmoidoscopy preparation.[see comment]. American Journal of Gastroenterology 1993, 88:1218-1223

14. Cohen SM, Wexner SD, Binderow SR, Nogueras JJ, Daniel N, Ehrenpreis ED, Jensen J, Bonner GF, Ruderman WB: Prospective, randomized, endoscopic-blinded trial comparing precolonoscopy bowel cleansing methods. Diseases of the Colon \& Rectum 1994, 37:689-696.

15. Frommer D: Cleansing ability and tolerance of three bowel preparations for colonoscopy. Diseases of the Colon \& Rectum 1997, 40:100-104.

16. Wruble L, Demicco M, Medoff J, Safdi A, Bernstein J, Dalke D, Rose M, Karlstadt RG, Ettinger N, Zhang B: Residue-free sodium phosphate tablets (OsmoPrep) versus Visicol for colon cleansing: a randomized, investigator-blinded trial. Gastrointestinal Endoscopy 2007, 65:660-670.

17. Belsey J, Epstein O, Heresbach D: Systematic review: oral bowel preparation for colonoscopy.[see comment]. Alimentary Pharmacology \& Therapeutics 2007, 25:373-384.

18. Tan JJ, Tjandra JJ, Tan JJY: Which is the optimal bowel preparation for colonoscopy - a meta-analysis. Colorectal Disease 2006, 8:247-258.

19. Felson DT, Anderson JJ, Meenan RF: The comparative efficacy and toxicity of second-line drugs in rheumatoid arthritis. Results of two metaanalyses.[see comment]. Arthritis \& Rheumatism 1990, 33:1449-1461.

20. Imperiale TF, Speroff T: A meta-analysis of methods to prevent venous thromboembolism following total hip replacement.[see comment][erratum appears in JAMA 1995 Jan 25;273(4):288]. JAMA 1994, 271:1780-1785.

21. DerSimonian R: Combining evidence from clinical trials. Anesth Analg 1990, 70:475-476.

22. Rapier R, Houston C: A prospective study to assess the efficacy and patient tolerance of three bowel preparations for colonoscopy. Gastroenterology Nursing 2006, 29:305-308.

23. Johanson JF, Popp JW Jr, Cohen LB, Lottes SR, Forbes WP, Walker K, Carter E, Zhang B, Rose M: A randomized, multicenter study comparing the safety and efficacy of sodium phosphate tablets with $2 \mathrm{~L}$ polyethylene glycol solution plus bisacodyl tablets for colon cleansing. American Journal of Gastroenterology 2007, 102:2238-2246.

24. Kastenberg D, Barish C, Burack H, Dalke DD, Duckor S, Putnam W, Valenzuela G, Group I-S: Tolerability and patient acceptance of sodium phosphate tablets compared with 4-L PEG solution in colon cleansing: combined results of 2 identically designed, randomized, controlled, parallel group, multicenter phase 3 trials. Journal of Clinical Gastroenterology 2007, 41:54-61.

25. Bitoun A, Ponchon T, Barthet M, Coffin B, Dugue C, Halphen M, Norcol G: Results of a prospective randomised multicentre controlled trial comparing a new 2-L ascorbic acid plus polyethylene glycol and electrolyte solution vs. sodium phosphate solution in patients undergoing elective colonoscopy. Alimentary Pharmacology \& Therapeutics 2006, 24:1631-1642.

26. Rostom A, Jolicoeur E, Dube C, Gregoire S, Patel D, Saloojee N, Lowe C: A randomized prospective trial comparing different regimens of oral sodium phosphate and polyethylene glycol-based lavage solution in the preparation of patients for colonoscopy.[see comment]. Gastrointestinal Endoscopy 2006, 64:544-552.

27. De Salvo L, Borgonovo G, Ansaldo GL, Varaldo E, Floris F, Assalino M, Gianiorio F: The bowel cleansing for colonoscopy. A randomized trial comparing three methods. Annali Italiani di Chirurgia 2006, 77:143-146, discussion 147.
28. Rex DK, Schwartz H, Goldstein M, Popp J, Katz S, Barish C, Karlstadt RG, Rose M, Walker K, Lottes S, et al: Safety and colon-cleansing efficacy of a new residue-free formulation of sodium phosphate tablets. American Journal of Gastroenterology 2006, 101:2594-2604.

29. Ker TS: Comparison of reduced volume versus four-liter electrolyte lavage solutions for colon cleansing. American Surgeon 2006, 72:909-911.

30. Tjandra JJ, Chan M, Tagkalidis PP: Oral sodium phosphate (Fleet) is a superior colonoscopy preparation to Picopre (sodium picosulfate-based preparation). Diseases of the Colon \& Rectum 2006, 49:616-620.

31. Hookey LC, Depew WT, Vanner SJ: Combined low volume polyethylene glycol solution plus stimulant laxatives versus standard volume polyethylene glycol solution: a prospective, randomized study of colon cleansing before colonoscopy. Canadian Journal of Gastroenterology 2006 20:101-105.

32. Hwang K-L, Chen WT-L, Hsiao K-H, Chen H-C, Huang T-M, Chiu C-M, Hsu G$\mathrm{H}$ : Prospective randomized comparison of oral sodium phosphate and polyethylene glycol lavage for colonoscopy preparation. World Journal of Gastroenterology 2005, 11:7486-7493.

33. Delegge $M$, Kaplan R: Efficacy of bowel preparation with the use of a prepackaged, low fibre diet with a low sodium, magnesium citrate cathartic vs. a clear liquid diet with a standard sodium phosphate cathartic. Alimentary Pharmacology \& Therapeutics 2005, 21:1491-1495.

34. Huppertz-Hauss G, Bretthauer M, Sauar J, Paulsen J, Kjellevold O, Majak B, Hoff G: Polyethylene glycol versus sodium phosphate in bowel cleansing for colonoscopy: a randomized trial. Endoscopy 2005, 37:537-541.

35. Hookey LC, Depew WT, Vanner SJ: A prospective randomized trial comparing low-dose oral sodium phosphate plus stimulant laxatives with large volume polyethylene glycol solution for colon cleansing. American Journal of Gastroenterology 2004, 99:2217-2222.

36. Barclay RL: Safety, efficacy, and patient tolerance of a three-dose regimen of orally administered aqueous sodium phosphate for colonic cleansing before colonoscopy. Gastrointestinal Endoscopy 2004, 60:527-533.

37. Tjandra JJ, Tagkalidis P: Carbohydrate-electrolyte (E-Lyte) solution enhances bowel preparation with oral fleet phospho-soda. Diseases of the Colon \& Rectum 2004, 47:1181-1186.

38. Law W-L, Choi H-K, Chu K-W, Ho JWC, Wong L: Bowel preparation for colonoscopy: a randomized controlled trial comparing polyethylene glycol solution, one dose and two doses of oral sodium phosphate solution. Asian Journal of Surgery 2004, 27:120-124.

39. Salwen WA, Basson MD: Effect of four-day psyllium supplementation on bowel preparation for colonoscopy:A prospective double blind randomized trial [ISRCTN76623768]. BMC Gastroenterology 2004, 4:2.

40. Schmidt L-M, Williams P, King D, Perera D: Picoprep-3 is a superior colonoscopy preparation to Fleet: a randomized, controlled trial comparing the two bowel preparations. Diseases of the Colon \& Rectum 2004, 47:238-242.

41. Rasmussen M, Bohlbro K, Qvist N: Oral sodium phosphate compared with water enemas combined with bisacodyl as bowel preparation for elective colonoscopy. Scandinavian Journal of Gastroenterology 2003, 38:1090-1094

42. DiPalma JA, Wolff BG, Meagher A, Cleveland Mv: Comparison of reduced volume versus four liters sulfate-free electrolyte lavage solutions for colonoscopy colon cleansing. American Journal of Gastroenterology 2003, 98:2187-2191.

43. Balaban DH, Leavell BS Jr, Oblinger MJ, Thompson WO, Bolton ND, Pambianco DJ: Low volume bowel preparation for colonoscopy: randomized, endoscopist-blinded trial of liquid sodium phosphate versus tablet sodium phosphate.[see comment]. American Journal of Gastroenterology 2003, 98:827-832.

44. Seinela L, Pehkonen E, Laasanen T, Ahvenainen J: Bowel preparation for colonoscopy in very old patients: a randomized prospective trial comparing oral sodium phosphate and polyethylene glycol electrolyte lavage solution. Scandinavian Journal of Gastroenterology 2003, 38:216-220.

45. Ell C, Fischbach W, Keller R, Dehe M, Mayer G, Schneider B, Albrecht U, Schuette W, Hintertux Study G: A randomized, blinded, prospective trial to compare the safety and efficacy of three bowel-cleansing solutions for colonoscopy (HSG-01*). Endoscopy 2003, 35:300-304.

46. Barclay RL, Depew WT, Vanner SJ: Carbohydrate-electrolyte rehydration protects against intravascular volume contraction during colonic cleansing with orally administered sodium phosphate.[see comment]. Gastrointestinal Endoscopy 2002, 56:633-638. 
47. Rex DK, Chasen R, Pochapin MB: Safety and efficacy of two reduced dosing regimens of sodium phosphate tablets for preparation prior to colonoscopy. Alimentary Pharmacology \& Therapeutics 2002, 16:937-944.

48. Kastenberg D, Chasen R, Choudhary C, Riff D, Steinberg S, Weiss E, Wruble L: Efficacy and safety of sodium phosphate tablets compared with PEG solution in colon cleansing: two identically designed, randomized, controlled, parallel group, multicenter phase III trials.[see comment]. Gastrointestinal Endoscopy 2001, 54:705-713.

49. Martinek J, Hess J, Delarive J, Jornod P, Blum A, Pantoflickova D, Fischer M, Dorta G: Cisapride does not improve precolonoscopy bowel preparation with either sodium phosphate or polyethylene glycol electrolyte lavage. Gastrointestinal Endoscopy 2001, 54:180-185.

50. Sharma VK, Schaberg JW, Chockalingam SK, Vasudeva R, Howden CW: The effect of stimulant laxatives and polyethylene glycol-electrolyte lavage solution for colonoscopy preparation on serum electrolytes and hemodynamics. Journal of Clinical Gastroenterology 2001, 32:238-239.

51. Young CJ, Simpson RR, King DW, Lubowski DZ: Oral sodium phosphate solution is a superior colonoscopy preparation to polyethylene glycol with bisacodyl. Diseases of the Colon \& Rectum 2000, 43:1568-1571.

52. Arezzo A: Prospective randomized trial comparing bowel cleaning preparations for colonoscopy. Surgical Laparoscopy, Endoscopy \& Percutaneous Techniques 2000, 10:215-217.

53. Chilton AP, O'Sullivan M, Cox MA, Loft DE, Nwokolo CU: A blinded, randomized comparison of a novel, low-dose, triple regimen with fleet phospho-soda: a study of colon cleanliness, speed and success of colonoscopy. Endoscopy 2000, 32:37-41

54. Lee J, McCallion $\mathrm{K}$, Acheson AG, Irwin ST: A prospective randomised study comparing polyethylene glycol and sodium phosphate bowel cleansing solutions for colonoscopy. Ulster Medical Journal 1999, 68:68-72.

55. Unal S, Dogan UB, Ozturk Z, Cindoruk M: A randomized prospective trial comparing 45 and $90-\mathrm{ml}$ oral sodium phosphate with X-Prep in the preparation of patients for colonoscopy. Acta Gastroenterologica Belgica 1998, 61:281-284

56. Sharma VK, Chockalingham SK, Ugheoke EA, Kapur A, Ling PH, Vasudeva R, Howden CW: Prospective, randomized, controlled comparison of the use of polyethylene glycol electrolyte lavage solution in four-liter versus two-liter volumes and pretreatment with either magnesium citrate or bisacodyl for colonoscopy preparation. Gastrointestinal Endoscopy 1998 47:167-171.

57. Sharma VK, Steinberg EN, Vasudeva R, Howden CW: Randomized, controlled study of pretreatment with magnesium citrate on the quality of colonoscopy preparation with polyethylene glycol electrolyte lavage solution. Gastrointestinal Endoscopy 1997, 46:541-543.

58. Hamilton D, Mulcahy D, Walsh D, Farrelly C, Tormey WP, Watson G: Sodium picosulphate compared with polyethylene glycol solution for large bowel lavage: a prospective randomised trial. British Journal of Clinical Practice 1996, 50:73-75.

59. Clarkston WK, Tsen TN, Dies DF, Schratz CL, Vaswani SK, Bjerregaard P: Oral sodium phosphate versus sulfate-free polyethylene glycol electrolyte lavage solution in outpatient preparation for colonoscopy: a prospective comparison. Gastrointestinal Endoscopy 1996, 43:42-48.

60. Thomson A, Naidoo P, Crotty B: Bowel preparation for colonoscopy: a randomized prospective trail comparing sodium phosphate and polyethylene glycol in a predominantly elderly population. Journal of Gastroenterology \& Hepatology 1996, 11:103-107.

61. Chia YW, Cheng LC, Goh PM, Ngoi SS, Isaac J, Chan ST, Ti TK: Role of oral sodium phosphate and its effectiveness in large bowel preparation for out-patient colonoscopy. Journal of the Royal College of Surgeons of Edinburgh 1995, 40:374-376.

62. Saunders BP, Masaki T, Fukumoto M, Halligan S, Williams CB: The quest for a more acceptable bowel preparation: comparison of a polyethylene glycol/electrolyte solution and a mannitol/Picolax mixture for colonoscopy. Postgraduate Medical Journal 1995, 71:476-479.

63. Afridi SA, Barthel JS, King PD, Pineda JJ, Marshall JB: Prospective, randomized trial comparing a new sodium phosphate-bisacodyl regimen with conventional PEG-ES lavage for outpatient colonoscopy preparation. Gastrointestinal Endoscopy 1995, 41:485-489.

64. Reiser JR, Rosman AS, Rajendran SK, Berner JS, Korsten MA: The effects of cisapride on the quality and tolerance of colonic lavage: a double-blind randomized study. Gastrointestinal Endoscopy 1995, 41:481-484
65. Golub RW, Kerner BA, Wise WE Jr, Meesig DM, Hartmann RF, Khanduja KS, Aguilar PS: Colonoscopic bowel preparations-which one? A blinded, prospective, randomized trial. Diseases of the Colon \& Rectum 1995 38:594-599.

66. Adams WJ, Meagher AP, Lubowski DZ, King DW: Bisacodyl reduces the volume of polyethylene glycol solution required for bowel preparation. Diseases of the Colon \& Rectum 1994, 37:229-233, discussion 233-224.

67. Marshall JB, Pineda JJ, Barthel JS, King PD: Prospective, randomized trial comparing sodium phosphate solution with polyethylene glycolelectrolyte lavage for colonoscopy preparation. Gastrointestinal Endoscopy 1993, 39:631-634.

68. Marshall JB, Barthel JS, King PD: Short report: prospective, randomized trial comparing a single dose sodium phosphate regimen with PEGelectrolyte lavage for colonoscopy preparation. Alimentary Pharmacology \& Therapeutics 1993, 7:679-682.

69. Clarkston WK, Smith OJ: The use of GoLYTELY and Dulcolax in combination in outpatient colonoscopy. Journal of Clinical Gastroenterology 1993, 17:146-148.

70. Lashner BA, Winans CS, Blackstone MO: Randomized clinical trial of two colonoscopy preparation methods for elderly patients. Journal of Clinical Gastroenterology 1990, 12:405-408

71. DiPalma JA, Marshall JB: Comparison of a new sulfate-free polyethylene glycol electrolyte lavage solution versus a standard solution for colonoscopy cleansing. Gastrointestinal Endoscopy 1990, 36:285-289.

72. DiPalma JA, McGowan J, Cleveland MV: Clinical trial: an efficacy evaluation of reduced bisacodyl given as part of a polyethylene glycol electrolyte solution preparation prior to colonoscopy. Alimentary Pharmacology \& Therapeutics 2007, 26:1113-1119.

73. Lichtenstein GR, Grandhi N, Schmalz M, Lottes SR, Forbes WP, Walker K, Zhang B: Clinical trial: sodium phosphate tablets are preferred and better tolerated by patients compared to polyethylene glycol solution plus bisacodyl tablets for bowel preparation. Alimentary Pharmacology \& Therapeutics 2007, 26:1361-1370.

74. Worthington J, Thyssen M, Chapman G, Chapman R, Geraint M: A randomised controlled trial of a new 2 litre polyethylene glycol solution versus sodium picosulphate + magnesium citrate solution for bowel cleansing prior to colonoscopy. Current Medical Research \& Opinion 2008, 24:481-488.

75. Ell C, Fischbach W, Bronisch $H-J$, Dertinger S, Layer P, Runzi M, Schneider T, Kachel G, Gruger J, Kollinger M, et al: Randomized trial of low-volume PEG solution versus standard PEG + electrolytes for bowel cleansing before colonoscopy. American Journal of Gastroenterology 2008, 103:883-893.

76. Szojda MM, Kuik DJ, Mulder CJJ, Felt-Bersma RJF: Colonic lavage with two polyethylene glycol solutions prior to colonoscopy makes no difference: a prospective randomized controlled trial. Scandinavian Journal of Gastroenterology 2008, 43:622-626

77. Chamberlain SM, Balart JC, Sideridis K, Salek J, Sridhar S, Thompson WO: Safety and efficacy of aspartame-based liquid versus sucrose-based liquids used for dilution in oral sodium phosphate solutions for colonoscopy preparations. Digestive Diseases \& Sciences 2007, 52:3165-3168.

78. Abdul-Baki H, Hashash JG, Elhajj II, Azar C, El Zahabi L, Mourad FH, Barada KA, Sharara Al, Abdul-Baki H, Hashash JG, et al: A randomized, controlled, double-blind trial of the adjunct use of tegaserod in wholedose or split-dose polyethylene glycol electrolyte solution for colonoscopy preparation. Gastrointestinal Endoscopy 68:294-300, quiz 334

79. Bektas H, Balik E, Bilsel Y, Yamaner S, Bulut T, Bugra D, Buyukuncu Y, Akyuz A, Sokucu N: Comparison of sodium phosphate, polyethylene glycol and senna solutions in bowel preparation: A prospective, randomized controlled clinical study. Digestive Endoscopy 2005, 17:290-296.

80. Macedo EP, Ferrari AP: Comparative study among three methods for oral colonoscopy preparation: Manitol, polyethylene glycol and oral sodium phosphate enema. Digestive Endoscopy 2003, 15:43-47.

81. Nagashima M, Okamura S, lizuka H, Ohmae $Y$, Sagawa T, Kudo T, Masuo T, Kobayashi R, Marubashi K, Ishikawa T, Oshimoto H, Yoshida M, Motegi K, Sakamoto T, lesaki K, Mori M: Mosapride citrate for colonoscopy preparation with lavage. Kitakanto Medical Journal 2002, 52:111-115.

82. Tantau M, Albu S: A comparative prospective study about preparation in colonoscopy using polyethyleneglycol versus Senna extract solution. Romanian Journal of Gastroenterology 1999, 8:29-31. 
83. Labenz J, Peitz U, Leverkus F, Borsch G: Bowel cleansing prior to colonoscopy: Golytely lavage versus a combination regime. European Journal of Gastroenterology and Hepatology 1991, 3:781-784.

84. Imperiale TF, Speroff T: A meta-analysis of methods to prevent venous thromboembolism following total hip replacement. JAMA 1994, 271:1780-1785.

85. Haas DM, Imperiale TF, Kirkpatrick PR, Klein RW, Zollinger TW, Golichowski AM, Haas DM, Imperiale TF, Kirkpatrick PR, Klein RW, et al: Tocolytic therapy: a meta-analysis and decision analysis. Obstetrics \& Gynecology 2009, 113:585-594.

86. Lumley T, Lumley T: Network meta-analysis for indirect treatment comparisons. Statistics in Medicine 2002, 21:2313-2324

87. Glenny AM, Altman DG, Song F, Sakarovitch C, Deeks JJ, D'Amico R, Bradburn M, Eastwood AJ, International Stroke Trial Collaborative G: Indirect comparisons of competing interventions. Health Technology Assessment (Winchester, England) 9:1-134.

88. Caldwell DM, Ades AE, Higgins JP, Caldwell DM, Higgins JPT: Simultaneous comparison of multiple treatments: combining direct and indirect evidence. BMJ 2005, 331:897-900.

89. Desmeules S, Bergeron MJ, Isenring P, Desmeules S, Bergeron MJ, Isenring P: Acute phosphate nephropathy and renal failure. New England Journal of Medicine 2003, 349:1006-1007.

90. Gonlusen G, Akgun H, Ertan A, Olivero J, Truong LD, Gonlusen G, Akgun H, Ertan A, Olivero J, Truong LD: Renal failure and nephrocalcinosis associated with oral sodium phosphate bowel cleansing: clinical patterns and renal biopsy findings. Archives of Pathology \& Laboratory Medicine 2006, 130:101-106.

91. Markowitz GS, Stokes MB, Radhakrishnan J, D'Agati VD, Markowitz GS, Stokes MB, Radhakrishnan J, D'Agati VD: Acute phosphate nephropathy following oral sodium phosphate bowel purgative: an underrecognized cause of chronic renal failure. Journal of the American Society of Nephrology 2005, 16:3389-3396.

92. FDA Safety Alert: Oral Sodium Phosphate (OSP) Products for Bowel Cleansing (December). 2008 [http://www.fda.gov/Drugs/DrugSafety/ PostmarketDrugSafetylnformationforPatientsandProviders/ucm 103354.htm].

93. Hookey LC, Depew WT, Vanner S, Hookey LC, Depew WT, Vanner S: The safety profile of oral sodium phosphate for colonic cleansing before colonoscopy in adults.[see comment]. Gastrointestinal Endoscopy 2002, 56:895-902.

94. Singal AK, Rosman AS, Post JB, Bauman WA, Spungen AM, Korsten MA: The renal safety of bowel preparations for colonoscopy: a comparative study of oral sodium phosphate solution and polyethylene glycol.[see comment]. Alimentary Pharmacology \& Therapeutics 2008, 27:41-47.

95. Brunelli SM: Association Between Oral Sodium Phosphate Bowel Preparations and Kidney Injury: A Systematic Review and Meta-analysis. Am J Kidney Dis 2009, 53(3):448-56.

96. Zwas FR, Cirillo NW, el-Serag HB, Eisen RN: Colonic mucosal abnormalities associated with oral sodium phosphate solution.[see comment]. Gastrointestinal Endoscopy 1996, 43:463-466.

\section{Pre-publication history}

The pre-publication history for this paper can be accessed here: http://www.biomedcentral.com/1471-230X/11/38/prepub

\section{doi:10.1186/1471-230X-11-38}

Cite this article as: Juluri et al:: Polyethylene glycol vs. sodium phosphate for bowel preparation: A treatment arm meta-analysis of randomized controlled trials. BMC Gastroenterology 2011 11:38.

\section{Submit your next manuscript to BioMed Central and take full advantage of:}

- Convenient online submission

- Thorough peer review

- No space constraints or color figure charges

- Immediate publication on acceptance

- Inclusion in PubMed, CAS, Scopus and Google Scholar

- Research which is freely available for redistribution

Submit your manuscript at www.biomedcentral.com/submit
Biomed Central 